\title{
Review: transvaginal ultrasonography, sonohysterography, and hysteroscopy have moderate accuracy in abnormal uterine bleeding
}

Farquhar C, Ekeroma A, Furness S, et al. A systematic review of transvaginal ultrasonography, sonohysterography and hysteroscopy for the investigation of abnormal uterine bleeding in premenopausal women. Acta Obstet Gynecol Scand 2003;82:493-504.

Clinical impact ratings GP/FP/Primary care $\star \star \star \star \star \star \star \star$ is 2 年

In premenopausal women with abnormal uterine bleeding (AUB), what is the diagnostic accuracy of transvaginal ultrasonography (TVUS), transvaginal sonohysterography (SH), and diagnostic hysteroscopy (DH) with biopsy?

\section{METHODS}

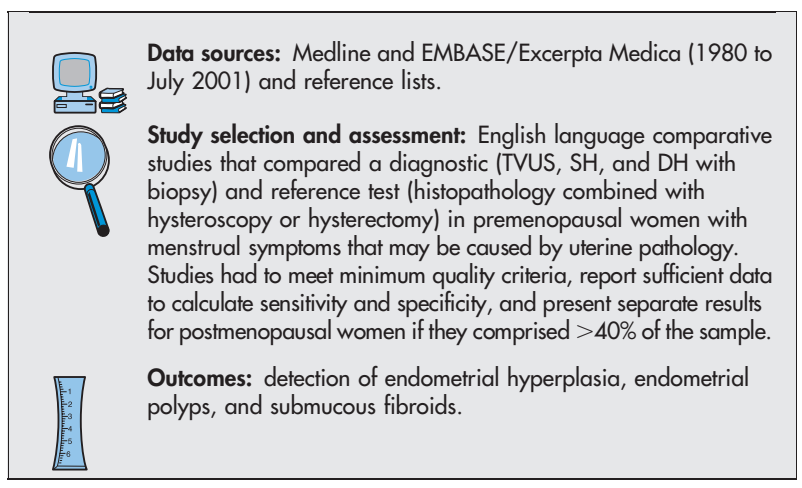

\section{MAIN RESULTS}

19 studies met the selection criteria. Mean age ranged from 38.5-49 years in 15 studies; 1 study reported the age range only (40-51 y), and 3 studies did not report age. The table shows the results.

\section{CONCLUSIONS}

In women with abnormal uterine bleeding, transvaginal ultrasonography (TVUS), sonohysteroscopy (SH), and diagnostic hysteroscopy (DH) are all moderately accurate for detecting intrauterine pathology. SH and DH seem better than TVUS for detecting submucous fibroids.

For correspondence: $\operatorname{Dr}$ C M Farquhar, University of Auckland, Auckland New Zealand. c.farquhar@auckland.ac.nz Source of funding: no external funding.

\begin{tabular}{|c|}
\hline 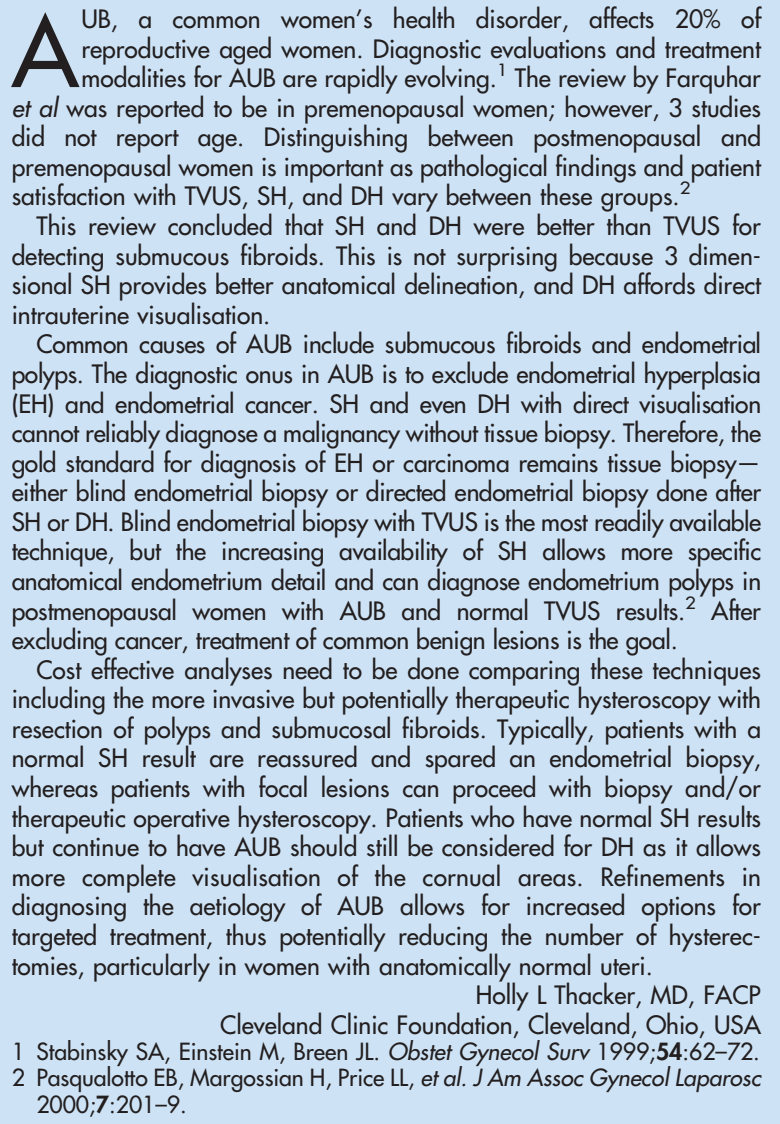 \\
\hline
\end{tabular}

Test characteristics for diagnosing submucous fibroids (SF), endometrial hyperplasia (EH), or any intrauterine pathology in abnormal uterine bleeding*

\begin{tabular}{|c|c|c|c|c|c|c|}
\hline Tests & Outcomes & Number of studies & Sens range & Spec range & $+\mathrm{LR}$ & $-\mathbf{L R}$ \\
\hline \multirow[t]{3}{*}{ TVUS } & All & 10 & $48-100 \%$ & $12-100 \%$ & $1.0-52$ & $0.057-0.79$ \\
\hline & SF & 9 & $21-100 \%$ & $53-100 \%$ & $1.6-62$ & $0.03-0.80$ \\
\hline & $\mathrm{EH}$ & 7 & $33-100 \%$ & $79-100 \%$ & $2.6-95$ & $0.04-0.75$ \\
\hline \multirow[t]{3}{*}{$\mathrm{SH}$} & All & 11 & $85-100 \%$ & $50-100 \%$ & $2.0-80$ & $0.12(0.08$ to 0.18$)$ \\
\hline & SF & 7 & $57-100 \%$ & $96-100 \%$ & $30(18$ to 50$)$ & $0.06-0.47$ \\
\hline & $\mathrm{EH}$ & 4 & $29-80 \%$ & $82-100 \%$ & $1.6-70$ & $0.14-0.87$ \\
\hline \multirow[t]{3}{*}{ Hysteroscopy } & All & 3 & $90-97 \%$ & $62-93 \%$ & $2.6-15$ & $0.07(0.04$ to 0.15$)$ \\
\hline & SF & 4 & $53-100 \%$ & $97-100 \%$ & $29(13$ to 65$)$ & $0.08-0.48$ \\
\hline & $\mathrm{EH}$ & 3 & $90-100 \%$ & $97-100 \%$ & 93 (42 to 204 ) & $0.05(0.02$ to 0.14$)$ \\
\hline
\end{tabular}

${ }^{*} \mathrm{SH}=$ sonohysterography; TVUS = transvaginal ultrasonography; Sens = sensitivity; Spec = specificity. Diagnostic terms defined in glossary. LR is reported as pooled summary estimate with $95 \% \mathrm{Cl}$ or as range. 